\title{
INFLUENCE OF SHORT-TERM TRAINING ON THE DISTAL ADJUSTMENTS OF REACHING IN PRETERM INFANTS
}

\author{
Elaine Leonezi Guimarães ${ }^{1}$, Andréa Baraldi Cunha², Daiane Munhoz Mira², Eloisa Tudella²
}

DOI: http://dx.doi.org/10.7322/jhgd.89621

\begin{abstract}
Object: The purpose of the study was to investigate the influence of short-term training on distal adjustments of reaching in preterm infants with low birth weight and compare them with full-term infants. Methods: Sixteen infants at the onset of reaching were equally allocated to a: preterm group ( $<34$ weeks of gestational age) with a low birth weight $(<2.5 \mathrm{~kg}$ ), and control group (full-term infants). The infants were submitted to two assessments carried out on a single day: pre-training ( 2 minutes) and post-training ( 2 minutes). The preterm group received one training session under a serial practice condition and the control group received one session of social training. It was used the repeated-measures analysis of variance, with Bonferroni adjustments. Results: The preterm infants presented more reaches with semi-open and oblique hand compared with the full-term infants and the short-term training increased more reaches and reaches with dorsal hand. Conclusion: We conclude that the preterm infants presented more reaches with semi-open and oblique hand compared with the full-term infants and that the short-term training was effective in providing more reaches, observed in the increase in the number of hand contacts with the object.
\end{abstract}

Keywords: Premature birth; Infant development; Movement training; Physical therapy.

\section{INTRODUCTION}

Prematurity and low birth weight are considered to be risk factors for delays in neuromotor development, as well as for injuries in cortical areas and neurological pathways responsible for vision, hearing and postural control.1,2 Thus, preterm infants born with low weight, for example, less than 37 weeks gestational age and birth weight less than 2.5 kilos, are most vulnerable to these risks which may interfere with the acquisition of motor skills in the first year of life. ${ }^{3,4}$ In general, preterm infants show motor differences when compared to full-term infants, and these differences may be present in the first months of life. Studies have shown that these motor differences are related to postural control, head control and motor skills such as hand function. 5,6,7,8 Related to manual abilities, reaching and grasping objects are highlighted. $8,9,10$

Reaching is defined as the ability to locate and touch an object in space, with one or both upper limbs, with or without grasping it. ${ }^{11,12}$ For objects to be reached and grasped accurately, it is necessary for the infant to find solutions to problems related to the presence of unknown external torques such as gravity and the tendency of the upper limb to sway. ${ }^{13,14}$ Thus, upper limbs adjustments are needed, especially distal adjustments, which are related to the positioning and opening of the hand and fingers to touch and grasp the object. ${ }^{15,16}$

In preterm infants at low risk of delays in neuromotor development, the few existing studies provide intriguing results regarding reaching ability. According to Fallang et al. ${ }^{17}$, these preterm infants ( \pm 30 weeks gestational age) at low-risk of delays in neuromotor development, at 4 months of corrected age, showed a greater frequency of reaching and of a higher quality (more fluent and slower reaches) than full-term infants. The authors concluded that preterm infants at low risk of delays in neuromotor development were at a temporary advantage due to longer extrauterine experience, allowing them to overcome the negative effects related to prematurity. ${ }^{17}$ However, other studies have suggested that preterm infants, at low risk of delays in neuromotor development, such as late preterm infants (34-36 weeks and 6 days gestational age) may differ in reaching strategies compared to full-term infants in later months. ${ }^{18}$ This fact can be observed in studies of late preterm infants, who at 6 months of corrected age, reached

\footnotetext{
1 Federal University of Triângulo Mineiro, Uberaba, Minas Gerais, Brazil.

2 Federal University of São Carlos, São Carlos, SP, Brazil.

Corresponding author: Elaine Leonezi Guimarães. E-mail: elaineleoneziguimaraes@gmail.com
}

Suggested citation: Guimarães EL, Cunha AB, Mira DM, Tudella E. Influence of short-term training on the distal adjustments of reaching in preterm infants. Journal of Human Growth and Development. 25(3): 263-270. Doi: http://dx.doi.org/10.7322/jhgd.89621 Manuscript submitted Oct 22 2014, accepted for publication Dec 192014. 
more often with open hand, reduced hand speed and increased deceleration of the hand to touch an object compared to full-term infants, which may reflect differences in the control of fingers and movements of arms and hands. ${ }^{15,12,18}$

In preterm infants $( \pm 27$ weeks gestational age) at high-risk of delays in neuromotor development and brain disorders, it was found that the acquisition of reaching occurred later, with the hand completing the trajectory more slowly, and in addition, with less fluent movements of the upper limbs than full-term infants. ${ }^{17,19}$ Such differences may be explained by deficits in postural control, in the control of axial motricity, in the development of oculomotor functions, in eye-hand and visual-motor coordination, low muscle tone and hyperextension of the trunk by these infants. ${ }^{19,8}$

Considering that prematurity has been linked to limitations in the behavior of manual reaching in the first months of life, it is very relevant to provide sensorimotor experiences in order to promote the improvement of reaching in infants, since the practice of a skill can lead to an improvement in its performance. ${ }^{11,20-25}$ In preterm infants of less than 33 weeks gestational age, it was found that 4-6 weeks of reaching training through object-oriented movements favored longer contact of the hand with the toy, and after 8 weeks of training showed more reaching with open hand and with the ventral surface of the hand than the untrained preterm infants, becoming quite similar to the reaching of full-term infants. ${ }^{10}$

It is known therefore that a long period of practice may provide beneficial changes in the behavior of the reaching of preterm infants. However, an important issue has been highlighted by researchers, who demonstrated that short periods of practice can influence the performance of a skill or a movement. $26,27,28$ In full-term infants, the authors demonstrated that a short training session in reaching, at the onset of the skill, was sufficient to increase the number of hand contacts with objects, with shorter and unimanual reaches, with oblique and semi-open hand. ${ }^{29,30}$ Soares et al. ${ }^{18}$ observed that at the onset of the skill, a short-term training under a serial practice condition on reaching in late preterm infants was effective in promoting an increase in the number of contacts of hands with objects and in bimanual reaches, immediately after the practice session, however, there was no retention of the effects obtained after 24 hours. ${ }^{18}$ Thus, short-term training in reaching can be considered to be an important tool for early intervention in preterm infants.

Although these studies demonstrate the effectiveness of specific training and short-term behavior in reaching, the effects of short-term training in preterm infants with low birth weight are incipient. It is known that prematurity and low birth weight are related to delays in neuromotor development and that short periods of practice can positively influence the performance of reaching in full-term and late preterm infants.

Thus, the objective is to analyse the influence of short-term training on distal adjustments of reaching (hand opening, surface of the hand contact, and hand orientation), at the onset of this ability in preterm infants with low birth weight and compare them with healthy and untrained full-term infants.

\section{METHODS}

\section{Design Overview and Participants}

This is a controlled clinical trial, parallel group design, with a convenience sample.

Eight infants born preterm (preterm group) with less than 34 weeks of gestational age and low birth weight $(<2.5 \mathrm{~kg})$ and, eight infants born fullterm and healthy (control group) participated in the study. Both groups of infants were at the onset of reaching (Table 1 ).

Table 1. Characterization of infants (mean values and standard deviation): gestational age (in weeks), birth weight (in kilograms), Apgar scores (first and and fifth minutes), age at the onset of reaching (in weeks), Time of assessment (days after the visit of reach onset identification)

\begin{tabular}{|c|c|c|c|c|c|c|c|c|}
\hline \multirow{2}{*}{ Infant } & \multirow{2}{*}{$\begin{array}{c}\text { Gestational } \\
\text { age } \\
\text { (weeks) }\end{array}$} & \multirow{2}{*}{$\begin{array}{l}\text { Birth } \\
\text { weight } \\
\text { (kilos) }\end{array}$} & \multicolumn{2}{|c|}{ Apgar scores } & \multirow{2}{*}{$\begin{array}{c}\text { Age at the } \\
\text { onset of } \\
\text { reaching (weeks) }\end{array}$} & \multirow{2}{*}{$\begin{array}{l}\text { Time of } \\
\text { assessment } \\
\text { (days) }\end{array}$} & \multicolumn{2}{|c|}{ Gender } \\
\hline & & & $1^{\prime}$ & $5^{\prime}$ & & & M & $\mathbf{F}$ \\
\hline $\begin{array}{l}\text { Preterm } \\
\text { Full-term }\end{array}$ & $\begin{array}{c}32.1 \pm 2.1^{*} \\
37.9 \pm 0.8\end{array}$ & $\begin{array}{c}1.711 \pm 0.4^{*} \\
2.816 \pm 0.4\end{array}$ & $\begin{array}{l}8.1 \pm 0.8 \\
9.1 \pm 0.6\end{array}$ & $\begin{array}{c}9 \pm 0.7 \\
9.8 \pm 0.3\end{array}$ & $\begin{array}{c}19.1 \pm 3.2^{* *} \\
14.4 \pm 1.7\end{array}$ & $\begin{array}{l}2.1 \pm 0.9 \\
2.1 \pm 0.4\end{array}$ & $\begin{array}{l}4 \\
3\end{array}$ & $\begin{array}{l}4 \\
5\end{array}$ \\
\hline
\end{tabular}

Note. $1^{\prime}$ : first minute, $5^{\prime}$ : fifth minute; M: male; F: female; $* p<.00 ;{ }^{* *} p<.03$.

\section{Procedures and Equipment}

The study was approved by the Ethics Committee of the University (protocol no. 1856/ 2011) and was prospectively registered in the Brazilian Clinical Trials Registry (protocol no. RBR4RJWRX).

Two weeks before the infants' three-month birthday, the examiner called their parents (twice a week) and invited them to participate. Moreover, the examiner made home visits in their residences in order to identify the onset of reaching. Reaching was defined as the act of locating an object in space, directing visual attention toward the object and directing one or both hands to it and touching it. 29,30

Once confirmed the onset of reaching, the Alberta Infant Motor Scale (AIMS) was administered by a single pediatric physical therapist and was use to ensure that all infants were similar in their motor development. ${ }^{31}$ After the AIMS assessment, the assessment was scheduled at the laboratory, which 
occurred no later than five days after the visit of reach onset identification (Table 1 ). Three cameras (frequency of $60 \mathrm{~Hz}$ ) were used to collect the data, which were positioned in order to become the reaching movements visible. The images were digitalized and analysed using the Dvideow system $5.0 \circledast{ }^{32,33}$

\section{Testing Procedures}

All infants were submitted to two assessments carried out in sequence on a single day: a pretraining ( 2 minutes) and a post-training assessments ( 2 minutes). The infants were in diapers and seated reclined $45^{\circ}$ from the horizontal in a baby chair. The examiner used her hands to support the infants at the height of the to provide security and trunk stability. ${ }^{29}$

An unfamiliar and attractive toy was presented at the infant's midline (xiphoid process-) within reaching distance for 2 minutes. ${ }^{29,30}$ The toy was carefully taken away and presented again after each successful reach and a 5-s interval was allowed between reaches. If the infant did not touch the toy, this was also taken away from the visual field of the infant and presented again to not allow habituation. ${ }^{12,29}$

\section{Reaching training protocol for preterm infants and social interaction protocol for full-term infants}

The preterm group received a single training session under a serial practice condition and the control group received one session of social training.

To conduct the reaching training protocol, each preterm infant was positioned at approximately $45^{\circ}$ reclined in the examiner's lap. Thus, the examiner sat comfortably with the trunk supported, with the legs slightly apart, with hips and knees flexed at about $120^{\circ}$ and $50^{\circ}$ degrees, respectively, measured using a goniometer. A small pillow was placed on the examiner's knees, and the infant's head was rested on it. This procedure sought to encourage the infant to remain face to face with the examiner, with the neck in semiflexion, facilitating alignment between the head and torso, and hands in the midline within the visual field (Figure $1 \mathrm{~A}-\mathrm{C}$ ). This training protocol described was based on studies by Cunha et al.29,30, Heathcock et al. ${ }^{10}$ and Lobo et al. ${ }^{34}$

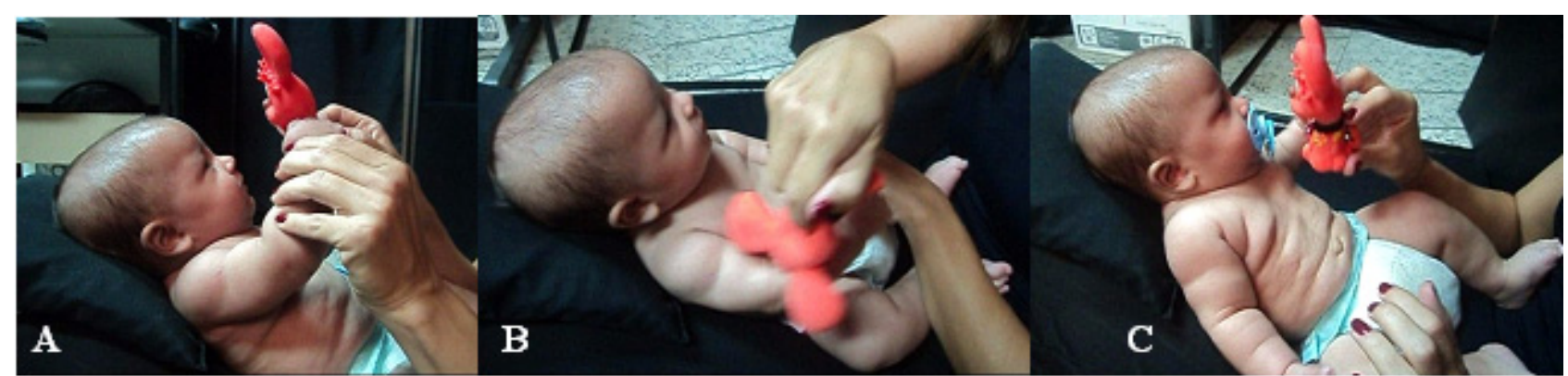

Figure 1 A-C. Reaching training protocol under a serial practice condition in $45^{\circ}$ reclined position.

The single session under a serial practice condition consisted of 3 activities (A, B, C) carried out for a period of 5 minutes. Each activity was performed 10 times for each member, i.e., $10 \mathrm{ti}-$ mes to the right arm and 10 times to the left arm, so that the same task was not repeated in consecutive attempts (e.g.: ABC, ABC, ABC). Activity $A$ consisted of the researcher holding the object in one hand, at the midline and at the height of the infant's xiphoid process, and with her other hand, holding the infant's forearm in order to guide that hand towards the object to touch it (Figure $1 A)$. For activity $B$, the upper limbs of the infant should be positioned by its sides. The researcher should then perform tactile stimuli with the object on the infant's arm and forearm and bring the object to the midline at the xiphoid process, within sight of the infant (Figure 1B). Activity $C$ consisted of the researcher holding the object in one hand, at the midline and at the height of the infant's xiphoid process, and waiting a few seconds to allow it to perform spontaneous uni- or multi-articulate movements of the upper limbs. If the infant did not touch or explore the object with the hand spontaneously, the researcher should undertake tactile stimuli with the object on the infant's stimulated hand. Each time the infant touched the object, the researcher should, with a smile, praise the child. If the infant grasped the object, the researcher should let him/her explore it (Figure 1C). To achieve the social interaction protocol, each full-term infant was seated reclined approximately $45^{\circ}$ in the researcher's lap for 5 minutes, similarly to that described in the previous protocol. The researcher only interacted with the infant visually and verbally, without touching their upper limbs or showing them objects. This protocol was based on studies Heathcock et al $^{10}$ and Soares et al. ${ }^{18}$

\section{Description of variables}

Reaching was coded when the infant's hand contacted the object, grasping or not the object. ${ }^{15}$ The infants should be directing their visual attention to the toy from the beginning to the object contact. ${ }^{30}$ The beginning of a reach was defined as the first frame when the infant's arm began an movement toward the object and the end of a reach as the first frame when the infant's hand touched the object. 35

The coding of reaches was performed blindly by three experienced observers. For each category of distal adjustments, interrater and intrarater agreements were calculated in $12.5 \%$ of the total 
sample using the equation [number of agreements /(number of agreements + number of disagreements)] $\times 100$. The mean value for interrater and intrarater agreement computed for hand opening was $92.4 \% \pm 1.2$, hand orientation was $94.2 \% \pm 1.2$, and, surface of the hand contact was $94.2 \% \pm 1.2$.

Total Reaching Frequency: Total number of reaches performed during each assesment, over a period of 2 minutes each. ${ }^{35}$

Distal Adjustments: were considered the adjustments made by the hand and fingers to touch the object. It was analysed: A) Hand opening: 1) open (when fingers were fully extended, 16,18 2) closed (when fingers were fully flexed), ${ }^{18}$ or 3 ) semiopen (when the fingers were in position between flexed and extended (regardless of degree), or even when only one or two fingers were flexed (regardless of the degree of flexion). ${ }^{15,18} \mathrm{~B}$ ) Hand orientation: a) horizontal (pronation- when the palm of the hand was faced downwards in relation to the forearm), 2) vertical (neutral position- when the palm of the hand was oriented toward the infant's midline in relation to the forearm ), and 3 ) oblique ( $45^{\circ}$ of hand/forearm supination- when the hand was in an intermediate position in relation to the two aforementioned positions. ${ }^{15,30} \mathrm{C}$ ) Surface of the hand contact: 1) dorsal hand: when the dorsal surface of the hand contacted touched the object, and 2) ventral hand: when the palm of the hand touched the object. ${ }^{10}$

\section{Statistical Analysis}

All the inferential procedures for homogeneity (Levene test) and normality of variances (ShapiroWilk tests) preceded the analyses. All the variables were analyzed using analysis of variance (ANOVA) for repeated measures and multiple comparisons, with Tukey test and Bonferroni adjustments. The factors considered were: group, assessment and interaction between these components. The total frequency of reaching was analyzed by frequencies of their occurrence and the distal adjustments were analyzed by the proportions of their occurrence in relation to the total frequency of reaching.

\section{RESULTS}

\section{Total Reaching Frequency}

There was a significant difference for group by assessment interaction $(F[2,14]=3.697$; $p=0.05)$. There was an increase in the number of reaches for the preterm group $(12.1 \pm 6.1 ; p=0.03)$ compared to the control group $(6.5 \pm 2.8)$ in the post-training. There were also an increase in the number of reaches for the preterm group in the post-training $(12.1 \pm 6.1 ; \mathrm{p}=0.017)$ compared to their pre-training (6.8 \pm 2.2 [Figure 2]). There was no difference between the preterm group and control group in the number of reaches in the pretraining $(p=0.777)$.

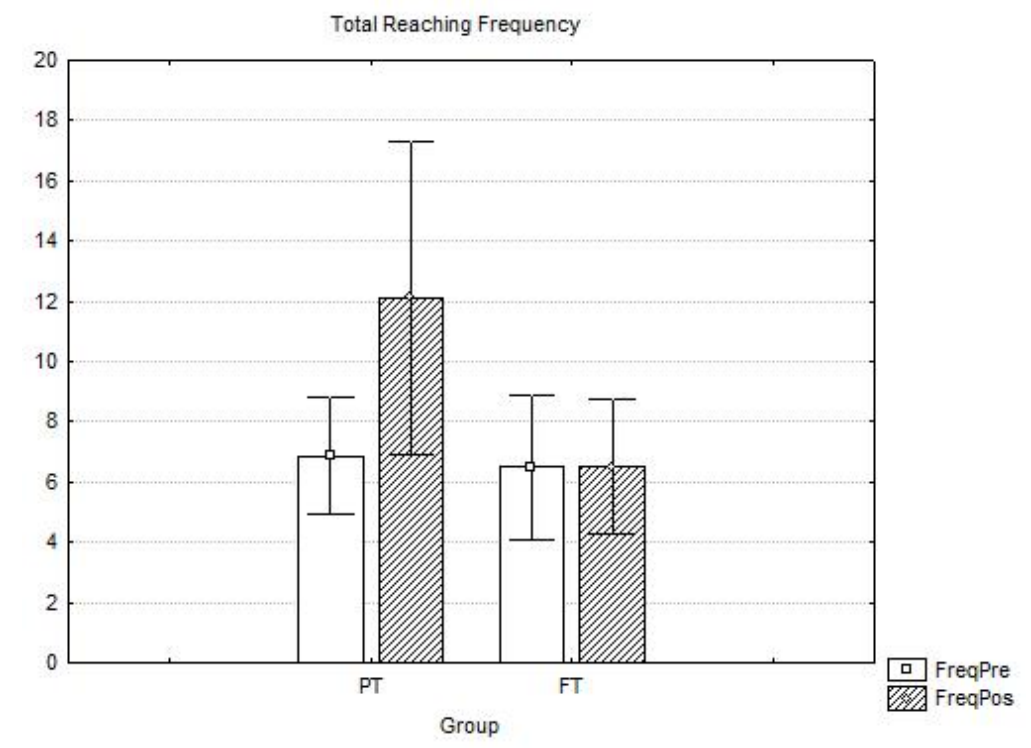

Note. PT: preterm group; FT: full-term (control group); FreqPre: number of reaches in the pre-training; FreqPos: number of reaches in the post-training.

Figure 2. Mean values and standard error of total frequency of reaching in the pre-training and post- training assessments in the preterm and control groups $(* p<.05)$

\section{Distal Adjustments}

For hand opening, there was a difference for group by variable interaction for semi-open hand $(F[2,14]=6.9 ; p=0.009)$, showing the boths groups presented more reaches with the semi-open hand in the post-training $(68.2 \pm 20.6)$ compared to the pre-training $(60.8 \pm 31.2)$. Moreover, there was a group $x$ assessment interaction (Figure 3 ) for semiopen hand $(F[2,14]=5.258 ; p=0.038)$, demonstrating a higher percentage of semi-open hand in the pre- and post-training for the preterm group (71.3 \pm 21.2$)$ compared to the control group

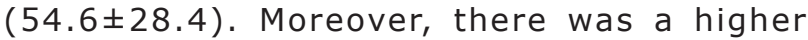
percentage of semi-open hand in the post-training

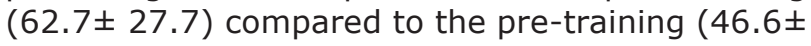
28.6) for the control group.

For hand orientation, there was significant difference for group by assessment interaction for oblique hand $(F[2,14]=4.3, p=0.05)$, with a greater percentage of oblique hand for the preterm group 


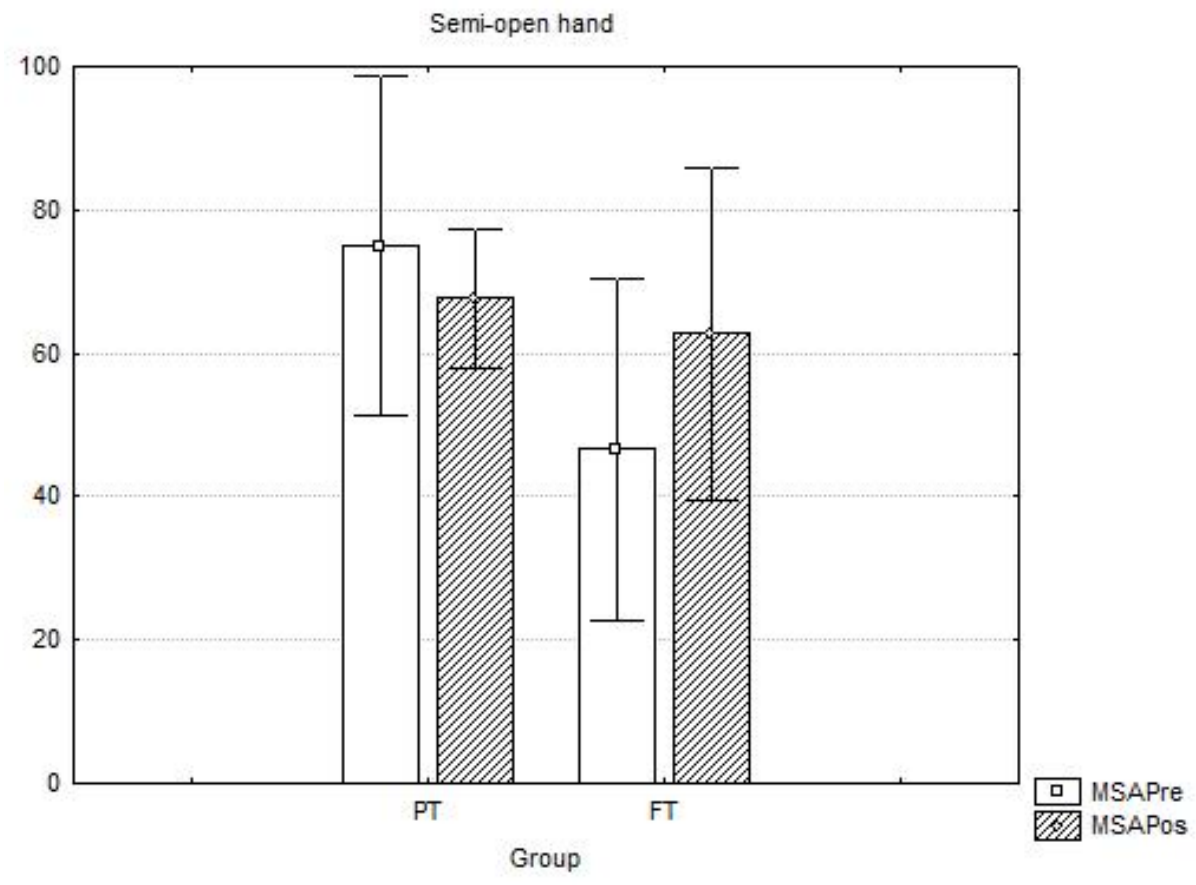

Note. PT: preterm group; FT: full-term (control group); MSAPre: percentage of semi-open hand in the pre-training; MSAPos: percentage of semi-open hand in the post-training.

Figure 3. Mean values and standard error of the percentage of the semi-open hand in the pre-training and posttraining assessments in the preterm and control groups $(* p<.05)$

$(43.6 \pm 21.7)$ compared to the control group (38.4 27.6$)$.

Related to surface of the hand contact (Figure 4), there was significant difference for dorsal hand for group by assessment interaction $(F[2,14]=4.4$, $\mathrm{p}=0.05)$, with the preterm group showing more dorsal hand contacts in the post-training (58.7 \pm 21.1$)$

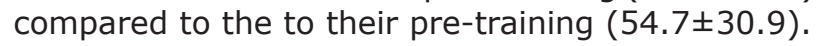

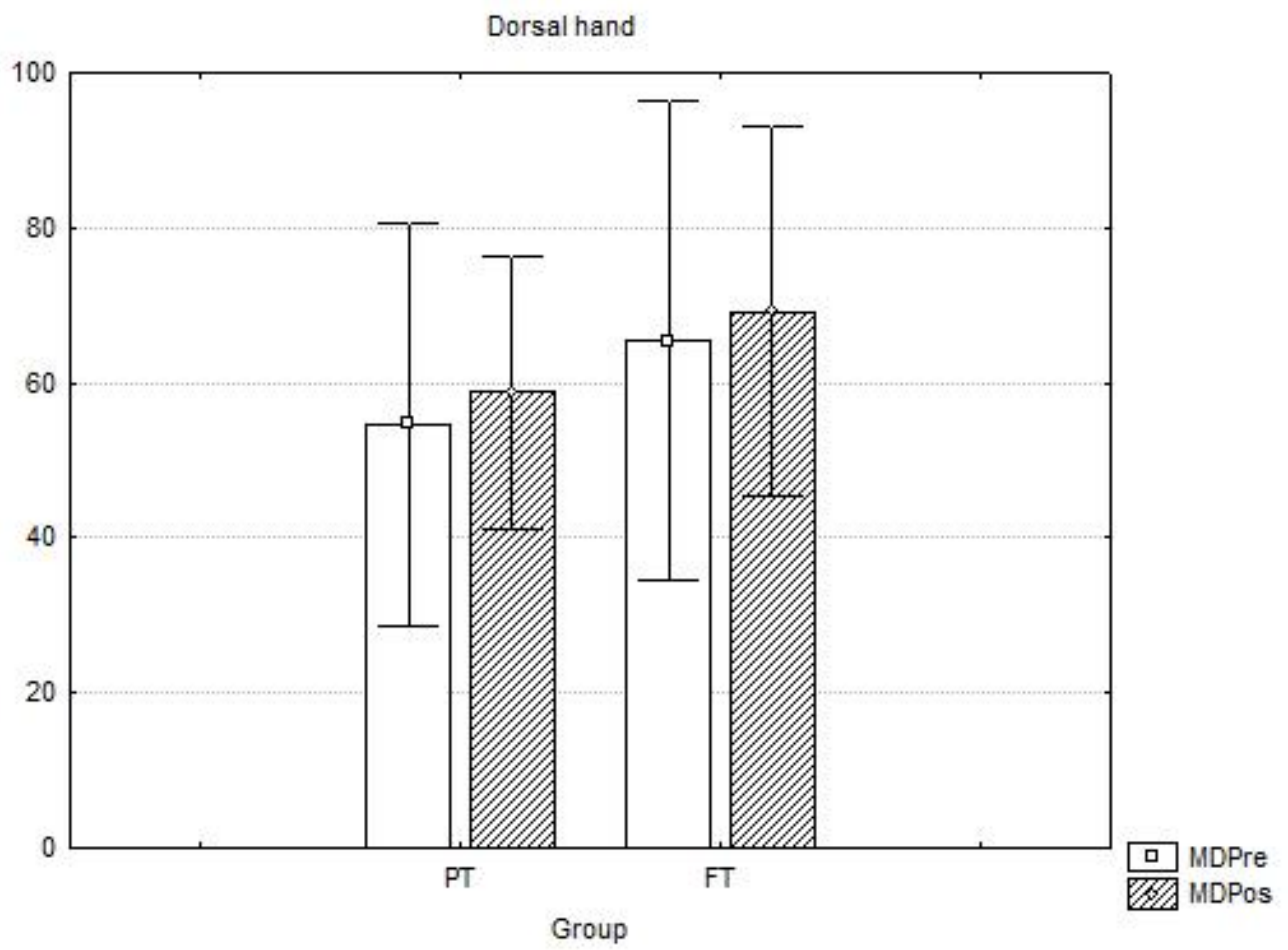

Note. PT: preterm group; FT: full-term (control group); MDPre: percentage of dorsal hand in the pre-training; MDPos: percentage of dorsal hand in the post-training.

Figure 4. Mean values and standard error of the percentage of the dorsal hand in the pre-training and post-training assessments in the preterm and control groups $(* p>.05)$ 


\section{DISCUSSION}

This study investigated the influence of shortterm training on the frequency and distal adjustments at the onset of reaching in preterm infants with low birth weight compared with fullterm infants, who did not receive any specific reaching training.

The study hypothesis was preterm infants that received a single session of short-term training under a serial practice condition, would present more efficient or similar reaches compared to fullterm infants who did not receive any training. The results showed that the short-term training promoted an improvement in task performance, observed in the higher number of reaches and reaches with the oblique and semi-open hand. Heathcock et al. ${ }^{10}$ also studied the reaching behavior of untrained full-term infants (social interaction for two weeks) and preterm infants (33 weeks of gestacional age and born weight less than 2.5 kilos [daily 20-minute reaching training for eight weeks). These authors found that after eight weeks of training, the trained preterm infants increased hand contacts with the object, presented more consistent reaches, a longer interaction with the toy, and performed reaches earlier than the full-term infants. The results of our study could be compared to the studies of Cunha et al. ${ }^{29}$ and Soares et al. ${ }^{18,36}$ which found that a single short training session was effective in increasing the number of reaches in fullterm and preterm infants. The authors concluded that the experience gained through the short-term practice may facilitate the selection of sensorimotor maps, resulting in a rapid improvement in the performance of a new skill. Thus, the improvement in task performance can occur by short-term trainings, i.e., after a single session.

Regarding the opening and orientation of the hand, it was observed that infants in both groups had a higher percentage of reaches with the semiopen hand in the post-training compared to their pre-training, especially for the control group. According to the literature, infants from 4 months of age are able to adapt to intrinsic and extrinsic constraints, being able to perform distal adjustments of reaching based on the physical properties of objects, such as size and rigidity. ${ }^{37,38}$ Therefore, we believe that the semi-open may be a strategy used by infants who suitably adjust the opening of the hand to the type of object presented. In this study, the infants may have been influenced by the physical properties of the object (small and soft), which did not require total opening of the hand. In addition, preterm infants had a higher percentage of reaches with the hand semi-open and oblique when compared to the control group. This result corroborates those found by Cunha et al. ${ }^{29}$ in full-term infants, which reported that in the onset of reaching, the semi-open and oblique hand seems to be the strategy used by infants, in order to adjust the hand to the object; and that the experience of a few minutes may have been sufficient to promote and increase affordance in relation to the object.

Moreover, the results regarding the opening of the hand, may be related to the results on the contact surface during reaching, in which trained preterm infants compared with full-term infants, had the highest percentage of reaches with the dorsal surface of hand and fingers. This fact can be explained by the reaching being accomplished with half-open hand and thus the dorsum of the infant's hands and fingers made the first contact with the object. In the study by Heathcock et al. ${ }^{10}$, preterm infants who received daily training of approximately 20 minutes after 8 weeks showed an increased frequency of reaching with an open hand and with the ventral surface, while the group born preterm who received only social interaction showed greater frequency in reaches with a closed hand and dorsal surface. Also, Cunha et al. ${ }^{39}$ have shown that full term infants presented more reaches with ventral hand after a short-term and goal-directed training. We can infer that although the preterm infants in our study increased their frequency of reaching, they were unable to perform reaches with the ventral hand after only one training session, which would be a more functional strategy for touching and grasping objects. We also can infer for the preterm infants maybe it is necessary more sessions of training to produce changes on this behavior.

As for the orientation of the hand, we found a predominance of reaches with oblique orientation of the hand relative to the horizontal and vertical orientation in preterm infants. According to the literature, it is still unclear how preterm infants perform these adjustments over the course of months. ${ }^{15}$ It is important to point out that the adoption of the oblique orientation of the hand suggests that infants are in a phase of refinement of reaching, this being an intermediate position between the horizontal and vertical position, and that the vertical hand, considered to be more efficient, would be adopted by the infant around 5 months of age, demonstrated by the progressive increase in forearm supination. ${ }^{37,16,15}$ We infer that training may contribute to the increased oblique hand in preterm infants, and that the object may have facilitated the supination of the forearm through the adoption of strategies to activate the forearm supinators, and consequently increase the oblique orientation hand.

It is important to consider that we did id not determine the longer-term effects of the short term training and a small sample may not represent the general population of infants. Thus, the generalization of results still requires more studies to verify the effectiveness of short-term training on the learning behavior of manual reaching in preterm infants. However, based on this study, we believe that further studies should be conducted to verify the impact of extrinsic factors such as the training of manual reaching on intrinsic factors such as prematurity. These studies may result in recommendations for preventative measures and intervention in neurosensorimotor dysfunctions associated with prematurity, preventing and/or minimizing possible complications.

We conclude that the preterm infants presented more reaches with semi-open and oblique hand compared with the full-term infants and that the short-term training was effective in providing 
more reaches, observed in the increase in the number of hand contacts with the object.

\section{ACKNOWLEDGEMENTS}

We kindly thank the families and infants for their participation in this study. We thank the support of research assistants from the Center of

\section{REFERENCES}

1. O'Connor AR, Stephenson T, Johnson A, Tobin MJ, Moseley MJ, Ratib S, et al. Long-term ophthalmic outcome of low birth weight children with and without retinopathy of prematurity. Pediatrics. 2002; 109(1): 12-8. DOI: http:// dx.doi.org/10.1542/peds.109.1.12.

2. Goyen $T A$, Todd $D A$, Veddovi $M$, Wright $A L$, Flaherty M, Kennedy J. Eye-hand coordination skills in very preterm infants 29 weeks gestation at 3 years: effects of preterm birth and retinopathy of prematurity. Early Hum Dev. 2006; 82(11):739-45. DOI: http://dx.doi.org/ 10.1016/j.earlhumdev.2006.02.011.

3. Caçola P, Bobbio TG. Baixo peso ao nascer e alterações no desenvolvimento motor: a realidade atual. Rev Paul Pediatr. 2010; 28(1): 70-6.

4. Guimarães EL, Tudella E. Reflexos primitivos e reações posturais como sinais indicativos de alterações neurosensoriomotoras em bebês de risco. Pediatria. 2003; 25(1/2):28-35.

5. Van der Fits IB, Flikweert ER, Stremmelaar EF, Martijn A, Hadders-Algra M. Development of postural adjustments during reaching in preterm infants. Pediatr Res. 1999;46(1):1-7.

6. Howard J, Parmelee AH Jr, Kopp CB, Littman B. A neurologic comparison of pre-term and fullterm infants at term conceptional age. J Pediatr. 1976;88(6): 995-1002.

7. Sommerfelt K, Pedersen S, Ellertsen B, Markestad T. Transient dystonia in nonhandicapped low- birthweight infants and later neurodevelopment. Acta Paediatr. 1996;85(12):1445-9. DOI: http://dx.doi.org/ 10.1111/j.1651-2227.1996.tb13950.x

8. Plantinga Y, Perdock J, de Groot L. Hand function in low-risk preterm infants: its relation to muscle power regulation. Dev Med Child Neurol. 1997;39(1):6-11.

9. Gorga D, Stern FM, Ross G, Nagler W. Neuromotor development of preterm and fullterm infants. Early Hum Dev. 1988;18(23):137-49. DOI: http://dx.doi.org/10.1016/ 0378-3782(88)90050-3

10. Heathcock JC, Lobo M, Galloway JC. Movement training advances the emergence of reaching in infants born at less than 33 weeks of gestational age: a randomized clinical trial. Phys Ther. 2008;88(3):310-22. DOI: http:// dx.doi.org/10.2522/ptj.200701453

11. Guimarães EL. Efeito do treino específico na habilidade de alcance manual em lactentes prétermo. Tese (Doutorado) - Universidade Federal de São Carlos. São Carlos: 2013.
Studies in Neuropediatrics and Motricity (Núcleo de Estudos em Neuropediatria e Motricidade - NENEM), Federal University of São Carlos, Brazil.

The study was conducted at the Federal University of São Carlos, São Paulo, in partnership with the Federal University of Triangulo Mineiro, Uberaba, Minas Gerais, Brazil, for initiation scientific from Daiane Munhoz Mira, academic of Physiotherapy, Federal University of São Carlos.

12. Toledo AM, Tudella E. The development of reaching behavior in low-risk preterm infants. Infant Behav Dev. 2008; 31(3):398-407. DOI: http://dx.doi.org/ 10.1016/j.infbeh.2007. 12.006

13. Konczak J, Borutta M, Dichgans J. The development of goal-directed reaching in infants. II. Learning to produce task-adequate patterns of joint torque. Exp Brain Res. 1997;113(3):465-74.

14. Out L, Van Soest AJ, Savelsbergh GJ, Hopkins $B$. The effect of posture on early reaching movement. J Mot Behav. 1998; 30(3): 26072. DOI: http://dx.doi.org/10.1080/00222 899809601341

15. Toledo AM, Soares DA, Tudella E. Proximal and distal of reaching behavior in preterm infants. J Mot Behav. 2011;43(2):137-45. DOI: http:// dx.doi.org/10.1080/00222895.2011.552076

16. Fagard J. Linked proximal and distal changes in the reaching behavior of 5- to 12-month-old human infants grasping objects of different sizes. Inf Behav Dev. 2000;23(3-4):317-29. DOI: http://dx.doi.org/10.1016/S01636383(01)00047-9

17. Fallang B, Saugstad OD, Grøgaard J, HaddersAlgra $M$. Kinematic quality of reaching movements in preterm infants. Pediatric Res. 2003; 53(5): 836-42. DOI: http://dx.doi. org/ 10.1203/01.PDR.0000058925.94994.BC

18. Soares DA, Van der Kamp J, Savelsbergh GJ, Tudella $E$. The effect of a short bout of practice on reaching behavior in late preterm infants at the onset of reaching: A randomized controlled trial. Res Dev Disabil. 2013;34(12):4546-58. DOI: http://dx.doi.org/10.1016/j.ridd. 2013.09.028

19. Ruas TCB, Gagliardo HR, Martinez CS, Ravanini SG. A Comparação de funções apendiculares desencadeadas pela visão em lactentes nascidos pré-termo e a termo no primeiro trimestre de vida. Rev Bras Crescimento Desenvolvimento Hum. 2010;20(3):680-7.

20. Heathcock JC, Galloway JC. Exploring objects with feet advances movement in infants born preterm: a randomized controlled trial. Phys Ther. 2009; 89(10): 1027-38. DOI: http:/dx. doi.org/10.2522/ptj.20080278

21. Needham A, Barrett T, Peterman K. A pickmeup for infants' exploratory skills: early simulated experiences reaching for objects using "sticky mittens"enhances young infants" object exploration skills. Inf Behav Dev. 2002; 25(3): 279-95. DOI: http://dx.doi.org/10.1016/S0 163-6383(02)00097-8 
22. Sveistrup $\mathrm{H}$, Woollacott $\mathrm{MH}$. Practice modifies the developing automatic postural response. Exp Brain Res. 1997;114(1):33-43. DOI: http:/ /dx.doi.org/10.1007/PL00005621

23. Vereijken B, Thelen E. Training infant treadmill stepping: the role of individual pattern stability. Dev Psychobiology. 1997;30(2):89-102. DOI: http://dx.doi.org/10.1002/(SICI) 1098 2302(199703)30:2<89::AID-DEV1>3.0.CO;2-Q

24. Zelazo NA, Zelazo PR, Cohen KM, Zelazo PD. Specificity of practice effects on elementary neuromotor patterns. Dev Psychol. 1993;29(4):686-91. DOI: http://dx.doi.org/ 10.1037/0012-1649.29.4.686

25. Zelazo PR, Zelazo NA, Kolb S. Walking in the newborn. Science. 1972; 176(4032): 314-15. DOI: http://dx.doi.org/10.1126/science. 176.4032 .314

26. Karni A, Bertini G. Learning perceptual skills: behavioral probes into adult cortical plasticity. Curr Opin Neurobiol. 1997;7(4):530-5. DOI: http://dx.doi.org/10.1016/S09594388(97)80033-5

27. Karni A, Meyer G, Rey-Hipolito C, Jezzard P, Adams MM, Turner $R$, et al. The acquisition of skilled motor performance: fast and slow experience-driven changes in primary motor cortex. Proc Nati Acad Sci U S A. 1998; 95(3): 861-8.

28. Luft AR, Buitrago MM. Stages of motor skill learning. Mol Neurobiol. 2005;32(3):205-16. DOI: http://dx.doi.org/10.1385/MN:32:3:205

29. Cunha $A B$, Soares DA, Ferro AM, Tudella E. Effect of training at different body positions on proximal and distal reaching adjustments at the onset of goal-directed reaching: a controlled clinical trial. Motor Control. 2013; 17(2): 123-44.

30. Cunha $A B$, Woollacott $M$, Tudella E. Influence of specific training on spatio-temporal parameters at the onset of goal-directed reaching in infants: a controlled trial. Braz J Phys Ther. 2013;17(4):409-417. DOI: http:// dx.doi.org/10.1590/S1413-3555201300 5000099

\section{Resumo}

Objetivo: O objetivo do estudo foi investigar a influência do treino de curta duração nos ajustes distais do alcance em lactentes pré-termo e baixo peso ao nascimento, e compará-los com lactentes a termo. Métodos: Dezesseis lactentes na emergência do alcance foram igualmente alocados em: grupo pré-termo ( $<34$ semanas de idade gestacional), e baixo peso ao nascimento $(<2,5 \mathrm{~kg}$ ), e grupo controle (lactentes a termo). Os lactentes foram submetidos a duas avaliações realizadas em um único dia: pré-treino ( 2 minutos) e pós-treino (2 minutos). O grupo pré-termo recebeu uma sessão de treino (prática variada seriada) e o grupo controle recebeu uma sessão de treino social. Foi utilizada a análise de medidas repetidas de variância, com ajustes de Bonferroni. Resultados: Os lactentes pré-termo apresentaram mais alcances com mão semi-aberta e oblíqua em comparação com os lactentes a termo. O treino de curta duração aumentou a frequência de alcances. Conclusão: Conclui-se que os lactentes pré-termo apresentaram mais alcances com mão semi-aberta e oblíqua em relação aos lactentes a termo e que o treino de curta duração foi efetivo na emergência do alcance, observando o aumento do número de contatos da mão do lactente com o objeto.

Palavras-chave: recém-nascidos prematuros, desenvolvimento infantil, treinando movimentos, fisioterapia. 